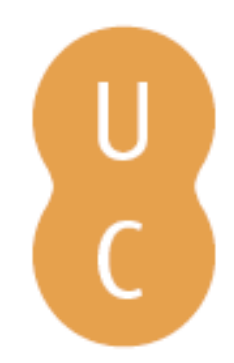

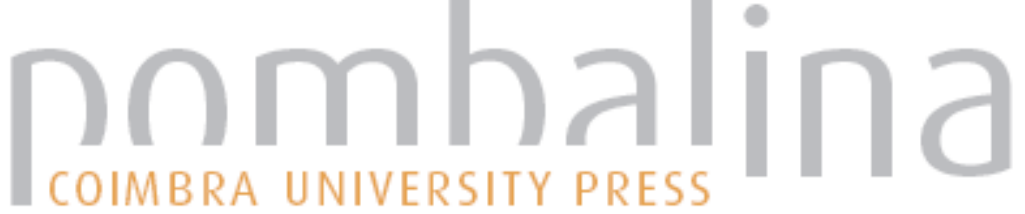

\section{El conocimiento pedagógico y la periferia del universo educativo}
Autor(es):
Ayuste González, Ana; Gros Salvat, Begoña; Romañá Blay, Teresa; Trilla Bernet, Jaume; Aznar Mínguet, Pilar; Requejo Osorio, Agustín; Rodríguez Martínez, Antonio

Publicado por: Imprensa da Universidade de Coimbra

URL persistente:

URI:http://hdl.handle.net/10316.2/38390

DOI:

DOl:http://dx.doi.org/10.14195/978-989-26-0486-2_12

Accessed : $\quad$ 26-Apr-2023 05:15:39

A navegação consulta e descarregamento dos títulos inseridos nas Bibliotecas Digitais UC Digitalis, UC Pombalina e UC Impactum, pressupõem a aceitação plena e sem reservas dos Termos e Condições de Uso destas Bibliotecas Digitais, disponíveis em https://digitalis.uc.pt/pt-pt/termos.

Conforme exposto nos referidos Termos e Condições de Uso, o descarregamento de títulos de acesso restrito requer uma licença válida de autorização devendo o utilizador aceder ao(s) documento(s) a partir de um endereço de IP da instituição detentora da supramencionada licença.

Ao utilizador é apenas permitido o descarregamento para uso pessoal, pelo que o emprego do(s) título(s) descarregado(s) para outro fim, designadamente comercial, carece de autorização do respetivo autor ou editor da obra.

Na medida em que todas as obras da UC Digitalis se encontram protegidas pelo Código do Direito de Autor e Direitos Conexos e demais legislação aplicável, toda a cópia, parcial ou total, deste documento, nos casos em que é legalmente admitida, deverá conter ou fazer-se acompanhar por este aviso.

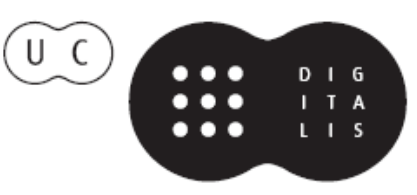


João Boavida

Ángel García del Dujo

Coordenação

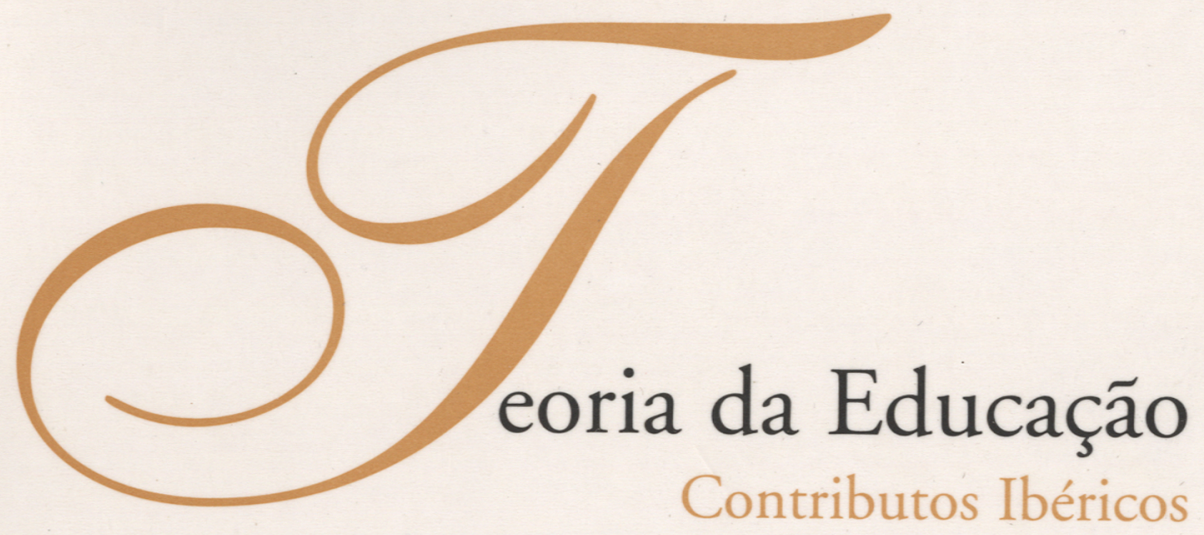


A na A yuste González

Begoña Gros Salvat

Teresa Romañá Blay

Jaume Trilla Bernet (coordinador)

Universidad de Barcelona

Pilar A znar M ínguet

Universidad de Valencia

A gustín Requejo Osorio

A ntonio Rodríguez Martínez

Universidad de Santiago de Compostela

El Conocimiento Pedagógico y I a Periferia del Universo Educativo

La Teoría de la Educación es conocimiento sobre la educación. Conocimiento sobre qué es y cómo es (descriptivo, explicativo, comprensivo, crítico...), sobre cómo debiera ser (teleológico, axiológico, político, ideológico...) y sobre cómo conseguir que lo sea (tecnológico, metodológico, normativo....). Pero, en cualquiera de tales dimensiones, este conocimiento dependerá, claro está, de qué es lo que se considere que incluye el universo de lo que llamamos educación; es decir, el conjunto de fenómenos (hechos, sucesos, procesos, situaciones, efectos...)(1) que denominamos educativos. Este universo ha ido creciendo a base de ir incorporando realidades antes inexistentes 0 fagocitando fenómenos que hasta el momento no se reconocían 0 aceptaban como educativos. Eso es prácticamente

\footnotetext{
(1), por extensión, también forman parte del universo educativo el conjunto de medios (instituciones, ámbitos, agentes...) que generan aquellos efectos.
} 
lo mismo que decir que el propio concepto de educación se ha ido ampliando, pues, al fin y al cabo, lo que aquí estamos llamando universo educativo no es otra cosa que el referente del significante «educación».

También es verdad, no obstante, que los cambios que se operan en el universo educativo no sólo son de naturaleza expansiva. En realidad, tales cambios son mucho más variados y complejos. A veces, además de incorporar nuevos elementos, desaparecen 0 se expulsan otros componentes tradicionalmente muy arraigados en lo considerado hasta entonces como educativo(2). En cualquier caso, la perspectiva histórica sobre el propio concepto de educación y sobre su universo referencial muestra que sus límites no son fijos sino dinámicos y evolutivos; que aquello que parecía perfectamente instalado en este universo pasa después a quedar excluido 0 a tomar en él un lugar simplemente residual $y$, por contra y sobre todo, que realidades o ámbitos que antes aparecían en el exterior, en la periferia o con un rol marginal, ahora las vemos plenamente integradas. Y todos estos movimientos que se producen en las fronteras de lo educativo obligan a ir modificando, consecuentemente, la Teoría de la Educación(3). A estas dinámicas que necesariamente han de producirse entre lo que se va incluyendo en el universo de la educación y los discursos (conceptos, teorías, reflexiones, investigaciones...) que sobre él se producen es a lo que está dedicado este artículo.

Después de unas breves anotaciones generales sobre los componentes del proceso educativo a partir de los que se genera la expansión del universo de la educación, reflexionaremos, tomando varios ejemplos concretos, sobre las dinámicas que se producen entre tal expansión y la teoría educativa.

(2) Por ejemplo, después de una larga y apabullante presencia del castigo físico en el universo educativo, en la actualidad, por considerar, con toda la razón del mundo, que no se trata de un recurso ni éticamente aceptable ni pedagógicamente eficaz, éste ha venido siendo desterrado de las prácticas educativas cotidianas.

(3) con más exactitud habría que decir que los cambios en el universo obligan a modificar también los otros componentes del discurso sobre la educación, puesto que la delimitación del universo educativo es también un producto discursivo, teórico. 
A pesar de la disparidad de contenidos que ofrecen los múltiples conceptos de educación, hay una serie de componentes que parecen esenciales a todos los procesos que llamamos educativos. En este sentido, e inspirándonos en una definición de educación que un autor alemán, H. Bokelmann, llamó directriz(4) podemos elaborar esta especie de estructura formal del concepto de educación:

Educación es la acción que $\mathrm{A}$ (<agente educativo)

realiza, directa o indirectamente, sobre B (.sujeto de la educación),

en unas condiciones determinadas $\mathrm{C}$ (contexto o medio educativo),

según unos principios $\mathrm{D}$ (principios o normas educativas')

que regulan unos procedimientos $\mathrm{E}$ (métodos educativos)

para que $\mathrm{B}$ incorpore unos contenidos $\mathrm{F}$ (contenidos educativos)

que produzcan en $B$ unos efectos $G$ (efectos educativos)

de acuerdo con ciertas finalidades $\mathrm{H}$ (fines de la educación)

Obviamente, con esta estructura formal no se aclara ninguno de los problemas de fondo relativos al concepto y universo de la educación, pero con ella se pueden analizar y contrastar las diversas soluciones que han sido propuestas a tales problemas. Esto es, los diferentes contenidos que cada concepto adjudica a los elementos (A, B, C...) de la estructura formal. Resolver el problema del concepto de educación y, por tanto, determinar la extensión del universo educativo, supone establecer quién (o qué) es o puede ser $\mathrm{A}(5)$, quién (o qué) es o puede ser $\mathrm{B}(6)$, qué tipo de efectos 0 transformaciones han de producirse en $B$ para que el proceso pueda ser considerado educativo, etc.

(4) La definición de Bokelmann dice: «Educación es la acción que los mayores (educadores), en el marco de ciertas representaciones de la vida (normas educativas) y en circunstancias concretas (condiciones de la educación), así como con determinados quehaceres (contenidos de la educación), con vistas a lograr una transformación (efectos de la educación), ayudan a los jóvenes (educandos) a dirigir su propia vida, y ello de tal forma que los jóvenes experimenten la acción educadora de los mayores como asistencia necesaria para su propia existencia y aprendan a enjuiciarla críticamente y a continuarla por sí mismos» (Bokelmann, 1981, p. 599).

(5) Es decir, el problema de la educatividad: ¿educan sólo los mayores, como decían las definiciones clásicas, o la madurez no es un requisito esencial?, ¿educan sólo individuos o también esta cualidad es atribuible a entidades supraindividuales como grupos, instituciones, generaciones...?, ¿puede calificar se como agentes educativos a realidades naturales como el clima, el paisaje...?

(6) 0 la cuestión de la educabilidad: isólo los seres humanos son educables?, ¿cuál es la especificidad educables de las per sonas adultas y de la tercera edad?... 
Las modificaciones habidas en el concepto y universo educativos que a continuación vamos a tomar como ejemplos para estudiar la repercusión de las mismas en la Teoría de la Educación se refieren a los elementos A, B, E y F. En primer lugar, nos referiremos a lo que ha supuesto para el discurso pedagógico la ampliación del universo educativo que comporta la consideración como agentes educativos a los comprendidos bajo las denominaciones de educación no formal e informal. En segundo lugar, haremos lo propio en relación a la idea de educación permanente, es decir, a la ampliación del universo educativo como consecuencia de entender que también los adultos y las personas mayores participan de la cualidad de educables y requieren, por tanto, las instancias educativas pertinentes. Analizaremos, en tercer lugar y manteniéndonos todavía en el ámbito de los sujetos de la educación, qué repercusiones tiene en el discurso pedagógico el reconocimiento efectivo de la igualdad de género ante el sistema educativo. A lo que suponen en relación al discurso las posibilidades que ofrecen las nuevas tecnologías para superar los límites de la presencialidad metodológica es de lo que trataremos en cuarto lugar. En quinto lugar, nos referiremos a un ejemplo relativo al elemento F: ¿qué supone para la teoría educativa la priorización de contenidos ambientalistas en la formación? Por último, reflexionaremos sobre la necesaria reconstrucción del discurso pedagógico cuando se pretende que la consideración de la corporeidad no sea sólo un lugar retórico(7).

\section{Las educaciones formal y no formal}

Cuando el discurso pedagógico empezó a tratar abundantemente de la educación no formal y de la informal(8), ellas estaban ya bien presentes.

(7) La redacción de esta introducción y del epígrafe 1 ha correspondido a J. Trilla; A. Requejo y A. Rodríguez se han encargado del epígrafe 2; el tercero es obra de A. Ayuste; el cuarto de B. Gros; el quinto de P. Aznar y T. Romañá ha escrito el sexto y último epígrafe.

(8) sobre estos conceptos y su historia: Coombs, 1968, 1985; Coombs \& Ahmed, 1974; Touriñan, 1983; Trilla, 1981, 1984, 1985, 1986, 1992. 
La educación informal (etiquetada así 0 de otro modo) ha existido siempre; y, si la no formal no ha existido siempre, es en cualquier caso anterior a la formal: antes de que hubiera escuelas y, mucho más aún, de que se constituyeran los sistemas educativos formales, habían instituciones, medios y ámbitos específica y metódicamente diseñados para educar. Lo que ocurrió es que, al menos desde el siglo XIX, la institución escolar y los sistemas educativos formales en los que ésta quedaba integrada tomaron tal protagonismo pedagógico que llegaron casi a monopolizar el discurso; como es tópico ya repetirlo, educación y escuela llegaron casi a confundirse y la mayor parte de la producción pedagógica se refería a aquella institución. Este panorama, sin embargo, fue cambiando significativamente durante la segunda mitad del siglo XX y particularmente a partir de finales de los años sesenta. Por un lado, factores diversos que hemos analizado en otra parte (Trilla, 1993, pp. 207 y ss.) crearán la necesidad de ir extendiendo cada vez más el sector educativo no formal; y, por otro lado, nuevas realidades (por ejemplo, la eclosión de los medios masivos de comunicación) obligarán a tomar en consideración los enormes efectos formativos (y deformativos) que ellas generan. Todo ello exigirá replantearse determinados aspectos del discurso pedagógico; por ejemplo, los siguientes.

Revisar el propio concepto de educación. Incluir en el universo educativo el sector no formal no supone ninguna modificación relevante del concepto de educación, pero aceptar que los procesos de aprendizaje y de formación de la personalidad desarrollados informalmente pueden merecer su presencia en aquel universo sí que obliga a ello. Obliga incluso a replantearse determinados aspectos que algunas concepciones de la educación habían considerado como esenciales. Por ejemplo, aquellos conceptos de educación que hacían de ella una tarea sistemática 0 metódica se verán como incompatibles con la «educación informal», a no ser que se entienda que es esa misma expresión la que constituye una contradicción en sus propios términos. Y la propia intencionalidad educativa como característica supuestamente esencial para que una determinada acción pueda ser llamada 
educativa, será también sometida a discusión por mor de la introducción de la educación informal en el debate teórico (Trilla, 1986, pp. 107-195).

Modificar las sistemáticas y ampliar las nomenclaturas. Otra de las consecuencias de la ampliación del universo educativo mediante las educaciones no formales e informales será la necesidad de rehacer la topología y la toponimia de este universo. En realidad, el propio sistema conceptual (educación formal, no formal e informal) constituye una taxonomía del universo educativo. Una taxonomía que, en rigor lógico, como ya fue destacado hace tiempo (Touriñan, 1983; Trilla 1985, 1986), no establece — como aparenta — tres tipos de educación, sino sólo dos y uno de ellos, a su vez, subdividido en otros dos: la informal, de una parte, y las no formal y formal en la otra. Sea como sea, esta nueva partición del universo educativa obliga a reconsiderar y resituar a otras taxonomías previas de tipos de educación y de agencias educativas, 0 incluso convierte en obsoletas a algunas de ellas. Por otro lado, la creciente presencia de lo no formal e informal en el universo educativo fuerza también a ciertos cambios terminológicos; porque, si lo formal se refirió básicamente a la escuela y priorizó lo docente, la enseñanza, la instrucción..., lo no formal y lo informal no han establecido tales dominancias, por lo que las adjetivaciones «escolares» tienden a substituirse por otras más compresivas que den cuenta también de lo que queda fuera de la institución docente por antonomasia: la organización escolar pasa a ser educativa, lo mismo ocurre con los departamentos y áreas de las administraciones públicas que, en lugar de ser de enseñanza serán también ahora de educación 0 formación, $y$, en fin, se multiplican los nombres de los oficios de la educación: ya no hay sólo maestros, profesores, docentes 0 enseñantes, sino también educadores sociales, especiales, especializados, animadores socioculturales, formadores de formadores, monitores, orientadores, tutores...

Elaborar modelos más comprensivos. La acción educativa en la escuela y también en la familia puede entenderse bastante bien a partir de modelos que las describen en tanto que relación personal y directa 
entre educador y educando (o grupo de educandos). Lo que hacen los maestros y maestras, madres y padres, es fundamentalmente hablar con sus alumnos/as o hijos/as: explican las lecciones, corrigen, aconsejan, castigan, estimulan, confortan..., todas ellas acciones casi siempre presenciales y que obedecen a un modelo simple «Educador-Educando». Sin embargo, muchas situaciones, experiencias y medios de educación informal y no formal no pueden describirse mediante este esquema tan sencillo. Efectos educativos generados a través de los medios de comunicación de masas, procesos de enseñanza-aprendizaje diseñados a partir de las nuevas tecnologías, efectos formativos producidos por el entorno urbano, cultural... todo ello no se explica bien mediante aquel modelo. Requiere formatos más complejos y comprensivos que incorporen la acción de agentes remotos, la compresión de los efectos formativos o deformativos de los medios en sí mismos considerados, la elucidación de la influencia difusa de los entornos o la elaboración de modelos para la configuración de escenarios educativos.

Comprender mejor la educación formal. Paradójicamente, la ampliación del universo educativo con los ámbitos no formales e informales no sólo obliga al discurso a convertirlos a ellos en objeto de estudio y a comprender mejor el proceso educativo global, sino que también tiene como efecto interpretar mejor el funcionamiento y la función de la educación formal. En realidad, antes incluso de la eclosión del discurso sobre las educaciones no formal y informal, algunos grandes pedagogos ya se habían dado cuenta de ello. Así, J. Dewey aludía a esto diciendo: «Exageramos el valor de la instrucción escolar, comparada con la que se gana en el curso ordinario de la vida. Debemos, sin embargo, rectificar esta exageración, no despreciando la instrucción escolar, sino examinando aquella extensa y más eficiente educación provista por el curso ordinario de los sucesos, para iluminar los mejores procedimientos de enseñanza dentro de las paredes de la escuela» (Dewey, 1918, p. 10)(9).

(9) a Freinet, por su parte, también le gustaba insistir en que los maestros debían aprender a enseñar observando cómo enseñan las madres. $Y$, por eso, el gran pedagogo francés habla de los »métodos naturales», del aprendizaje por «ensayo y error», del «tanteo experimental», etc., 
Especificidades forzadas y el efecto pendular. Pero no todas las consecuencias discursivas de la ampliación, con las educaciones no formal e informal, del universo educativo resultan positivas. También se producen algunos efectos indeseables; señalaremos un par de ellos. Ambos —que seguramente se dan no sólo respecto a la educación no formal e informal, sino también en la mayoría de los casos que veremos en los siguientes apartados — surgen de la necesidad que se experimenta desde estos nuevos ámbitos de encontrar su lugar, de legitimar su presencia y de afianzarse en el universo educativo. El primero de estos efectos consiste en la elaboración de un discurso que tiende a enfatizar la identidad y las especificidades de los ámbitos en cuestión. Un discurso identitario que realza las diferencias con lo que hasta entonces ha tenido el papel preponderante en el universo educativo; un discurso que, por lo que se refiere a la educación no formal, se ocupa sobre todo en desmarcarse de la escuela, convirtiendo erróneamente a ambos tipos de educación no sólo en diferentes sino además en antagónicos entre sí. Es cuando se intenta convertir a la educación no formal en el remedio de todos los males de la formal y en una suerte de panacea del sistema educativo. Este es el segundo efecto negativo que anunciábamos, un efecto pendular: la magnificación desproporcionada de lo nuevo 0 emergente con la consiguiente, y casi siempre injusta, depreciación de lo que se ha descrito, también impropiamente, como antitético. En este sentido, y como ejemplo, hay que citar algunas de estas tablas que pretenden establecer comparativamente las características de la educación no formal respecto de la formal y que, de la manera más maniquea posible, hacen recaer en la columna de la primera los rasgos más pedagógicamente indeseables, para anotar en el haber de la segunda todas las virtudes pedagógicas imaginables.

nombres bien expresivos de la voluntad de aprender para la escuela de las formas que han tratado de extraer consecuencias pedagógico-escolares de los estudios sobre educación informal (Scribner \& Colé, 1973). 0 también la obra tan interesante de D. A. Schón, La formación de profesionales reflexivos, que propone modelos de enseñanza profesional bien próximos a los procedimientos artesanales (Schón, 1992). Y, en fin, para no multiplicar posibles referencias, la obra de H. Gardner (1991) cuyo título y subtítulo ya dicen bastante: The unschooled Mind. How Children Think \& How Schools Should Teach. 
El discurso de lo emergente tiende a idealizarlo con el coste de denigrar, a menudo indiscriminada y arbitrariamente, a lo que estaba bien instalado en el universo educativo. Tampoco hay que olvidar que el despliegue inicial de los discursos sobre la educación no formal (más o menos, por la década de los años setenta del siglo XX) coincide significativamente con la aparición de los acérrimos e hipercríticos discursos contra la institución escolar: propuestas desescolarizadoras, paradigma de la reproducción, crítica foucaultiana... Parecía olvidarse que casi todas estas críticas contra la escuela —algunas de ellas tan lúcidas como despiadadas — podrían aplicarse indistintamente a buena parte de la educación no formal, la cual, como decíamos en otro lugar, "puede albergar idénticos males que, en su caso, puedan aducirse a la escolar. La educación no formal puede ser tan clasista, alienante, burocrática, ineficaz, onerosa, obsoleta, estática, manipuladora, estereotipada, uniformizadora, etc., como lo pueda ser la formal. Y, aún, en alguna de estas cosas bien pudiera ser peor la no formal, por aquello de que la otra es, de cualquier forma, un «mal conocido». La misma novedad de los medios no formales, y su apariencia de panacea, pueden contribuir a disimular sus propios defectos» (Trilla, 1993, pp. 221 y ss.).

\section{La educación de personas adultas y de la tercera edad}

Tal como se ha señalado anteriormente, la preponderancia de la educación formal y la consideración de la acción educativa centrada en la institución escolar decantaron una intervención educativa centrada sobre todo en las primeras etapas de la vida. La constitución de los sistemas educativos nacionales que se afianzan en Europa a partir del siglo XIX (Ley Moyano en España, 1857) asumió la importancia de la educación de la infancia y de la juventud tratando de extender la enseñanza reglada elemental y media a estas etapas. El mundo de los adultos, en gran medida, quedará al margen de estas oportunidades. 
A pesar de esta situación, las iniciativas de educación no formal se multiplicaron desde finales del XIX (Ateneos, acciones de Extensión Universitaria, Universidades Populares, Sindicatos, etc.) tanto para dar respuestas a las necesidades básicas (analfabetismo, falta de formación básica, etc.) como a las situaciones laborales y político-sociales que afectan a la vida adulta.

Fundamentalmente, será el imperativo práxico quien guíe las intervenciones en el campo de la educación de personas adultas. La propia UNESCO reconoce que la educación permanente procede de especialistas y animadores de educación de adultos en medios externos al sistema escolar y que están más en consonancia con la realidad socioeconómica. La teorización más constante y consolidada sobre la educación de personas adultas discurrirá por diferentes caminos: uno, más «institucional», donde algunos organismos internacionales ejercen una influencia importante a través de sus informes y encuentros (UNESCO/OCDE etc.); otro, más orientado hacia interpretaciones centradas en modelos políticos, en consideraciones operativas sobre los procesos de aprendizaje 0 en una visión crítica que incide sobre su naturaleza política. Finalmente, en las tres últimas décadas surgen estudios y propuestas referidas específicamente al grupo emergente de los adultos mayores, cuya presencia más numerosa y constante en nuestra sociedad está obligando a replantear nuevas intervenciones educativas en este campo.

\subsection{La interpretación institucional}

Nadie puede negar a la UNESCO haber marcado tanto a nivel teórico como político las pautas para extender la educación más allá de la escuela, a través de sus publicaciones, encuentros internacionales y actividades informales. En este ámbito toma relevancia el informe Faure (1972) y su propuesta de la «ciudad educativa». Se trata de restituir a la educación las dimensiones de la existencia vivida, redistribuyendo la enseñanza en el tiempo y en el espacio. La ciudad debe convertirse en una agencia educativa 
que tratará de integrar el sistema formal con los otros sistemas, no formal e informal. Una propuesta que ha tenido su operatividad — no siempre plenamente conseguida —en el movimiento de «ciudades educadoras».

Con el horizonte del siglo XXI, el informe Delors (1996) destaca el aumento significativo de la educación de adultos que, como verdadera explosión, debe adoptar formas múltiples (formación básica en un marco educativo extraescolar, cursos de idiomas, capacitación profesional y actualización de conocimientos, formación en diferentes asociaciones 0 sindicatos, sistemas de aprendizaje abiertos y a distancia etc.).

Este marco institucional no está exento en la praxis de la dialéctica entre una educación de personas adultas por «imperativo económico», defendida a veces a ultranza por la política neoliberal (creación de unas estrechas relaciones entre aprendizaje y mundo del trabajo), y la dimensión más social y humanística (imperativo democrático). Los espacios educativos de la educación de adultos para el siglo XXI abarcan tanto la familia como el entorno comunitario, el tiempo libre, los medios de comunicación y el medio laboral, estableciéndose una interrelación mutua. La educación de adultos debe combinar conocimientos formales y no formales, el desarrollo de aptitudes innatas y la adquisición de competencias. Debe permitir a los adultos tomar conciencia de sí mismos y de su entorno y desempeñar una función social en el mundo del trabajo y en la vida pública a través del saber, saber hacer, saber ser y saber convivir.

La interpretación institucional de la educación de adultos seguirá viviendo esta dialéctica entre una consideración profundamente humanista (superar toda concepción que sea estrechamente utilitarista) y las implicaciones económicas y sociales que tiene todo proceso educativo y desde las que se insistirá en las teorías socioeconómicas del capital humano basadas sobre todo en la economía del saber. 
2.2. Desarrollo humano y dimensión político-social de la educación de adultos

A la hora de abordar la interpretación compleja de la educación de adultos, no es posible acudir a un marco interpretativo único que acoja los numerosos ámbitos de actividad, los diferentes objetivos y finalidades. Son múltiples los diferentes análisis teóricos, que se concentran en dos perspectivas: la consideración general sobre el desarrollo humano y la dimensión política.

La denominada genéricamente «teoría del ciclo vital» ha insistido en la plasticidad y el potencial para el cambio evolutivo que se opera durante toda la vida. Sus trabajos rechazan que los estadios infantiles sean determinantes para el desarrollo posterior y suelen ser más sensibles a la influencia del medio y de la cultura que a los procesos internos. La adultez sigue siendo un período de transformaciones tanto en los aspectos biológicos como psicológicos y sociales. El desarrollo es multidireccional y depende fundamentalmente del contexto social y cultural. Sin negar la importancia de las experiencias tempranas, se afirma que no son tan determinantes en la edad adulta. El desarrollo de la adultez depende tanto de la niñez como de las posibilidades de aprendizaje y de la variabilidad intercomportamental que engloban los diferentes sucesos de vida, los factores derivados de la evolución de las sociedades, etc.

En lo que se refiere al aprendizaje son múltiples los enfoques, centrados unos en la importancia de las personas (teorías humanistas y psicoanalíticas) y resaltando otros la perspectiva del entorno social. Desde distintas corrientes, la educación de adultos asume una teorización y praxis que se asientan en consideraciones andragógicas cuyo soporte más importante son las experiencias de vida; en el aprendizaje adulto tiene muy poco que ver el modelo escolar.

La importancia de los contextos sociohistóricos (su lectura e interpretación) es, sobre todo, puesta de relieve por las denominadas teorías críticas. En la edad adulta el proceso educativo no puede limitarse a transmitir conocimientos, hechos, datos, etc., sino a construir conocimientos, lo que supone tratar de entender la realidad en base a la capacidad de desvelar situaciones y razones 
que determinan una praxis social, cultural y económica en un preciso momento histórico. Esta concepción dialéctica de la educación de adultos se expresa en la metáfora freiriana «educación bancaria versus educación liberadora».

\subsection{Los adultos mayores y su problemática específica: del paradigma asistencialista al paradigma intervencionista}

La esperanza de vida ha generado un numeroso grupo de adultos, los hoy denominados «mayores». Su esperanza de vida, así como el interés por su formación, han ido incrementándose con el tiempo. La visión «asistencial» de este grupo ha sido superada por la «intervencionista». Los presupuestos de diversas teorías e investigaciones (teorías genéticas asociadas exclusivamente a los cambios biológicos versus teorías de la continuidad, teoría de la actividad versus teoría de la desvinculación y el «retiro», etc.) inciden en destacar que el comportamiento de este grupo de edad sólo en una pequeña parte está determinado de manera biológica y, en cambio, se encuentra estrechamente relacionado con factores ambientales y socioculturales.

Esta comprensión pluridimensional y comprensiva es la que da lugar a una elaboración completa y global de programas sociales y educativos para superar los mitos y estereotipos infundados y construir una imagen social de la vejez: la denominada vejez exitosa frente a la resignación de ser viejo.

La teoría y praxis de la Gerontología Educativa han sacado de la penumbra la expresión «educación de personas mayores». La Gerontología Educativa, interesándose por las cuestiones educativas básicamente de ámbitos no formal e informal, propone que esta etapa de la vida no tiene por qué significar un rol negativo (mitología de la decrepitud). Lo importante en estas edades es proporcionar experiencias de aprendizaje estimulante y desarrollar programas educativos específicos acordes con esta etapa de la vida adulta.

Un modelo de este tipo de intervenciones son los Programas Universitarios para Mayores, que estos últimos años están teniendo un 
gran desarrollo en las universidades españolas; en la actualidad son alrededor de cincuenta universidades las que tienen estos programas y, según estimaciones de la Asociación Estatal de Programas Universitarios de Mayores (AEPUM), están matriculados más de 30.000 alumnos.

Estos programas surgieron como respuesta a la demanda formativa de un grupo de población cada vez más numeroso, que llega en relativamente buenas condiciones físicas y mentales a edades cada vez más altas y que en un porcentaje muy elevado no pudo acceder, por diferentes causas, a la Universidad y que ahora desearía poder asistir a sus aulas. Este hecho se conjuga con el intento de apertura de las universidades a toda la población, con el intento, en el fondo, por parte de la academia de democratizar el conocimiento y el saber. Por tanto, estos programas articulan sus fines desde una doble perspectiva: por un lado, son programas con una importante proyección social y, por otro, tienen un eminente carácter formativo y educativo desde la perspectiva del crecimiento y desarrollo personal en la formación a lo largo de toda la vida.

De ahí que, entre los fines de estos programas, esté el de democratizar el conocimiento, abriendo sus puertas a todas las personas mayores, en algunos casos para que puedan acceder a sus aulas por primera vez, favoreciendo su integración y participación en unos procesos formativos que respondan a las necesidades y expectativas de este colectivo social. En este sentido, podemos decir que los tres grandes objetivos de estos programas son los siguientes: facilitar a los participantes el acercamiento a la Universidad e impulsar las relaciones intergeneracionales; promover su incorporación a los estudios universitarios y la participación en procesos formativos con la doble finalidad de fomentar la promoción personal e intelectual y la mejora de la calidad de vida y, finalmente, vincular y ampliar la oferta de estudios universitarios, con criterios de interdisciplinariedad, impulsando programas de desarrollo científico y sociocultural adaptados a las expectativas y necesidades de los ciudadanos.

Si bien los fines y los objetivos son similares, la respuesta que dieron las universidades fue distinta, lo que dio lugar a una gran variedad de programas que 
se está tratando de unificar. En esta línea se vienen celebrando los encuentros nacionales de Programas Universitarios de Mayores, el último celebrado en el 2004 en Coreses (Zamora), en los que se está intentando elaborar un programa marco: establecer un número similar de cursos, de créditos, tipo de profesorado, etc.

La mayoría de ellos tienen en común, dentro de lo que es la formación a lo largo de toda la vida, el estar dirigidos a personas mayores de 50 ó 55 años; en algunos casos es el único requisito para matricularse, junto con su carácter universitario, es decir, que comparte los mismos requisitos académicos, exceptuando los jurídico-legales, que las titulaciones normales (en varias universidades están equiparados a los títulos propios).

Finalmente, con independencia del logro de los objetivos y de las diferencias entre programas, parece cierto, por los estudios que se vienen realizando, que los alumnos de estos programas tienen una mejor calidad de vida, mantienen unos niveles cognoscitivos superiores al resto de la población de su edad, manifiestan tener menos dolencias físicas y psíquicas, establecen más relaciones con personas que están fuera de su entorno familiar 0 comunitario, etc. Consideramos, por tanto, que estos programas tienen una importancia social, sanitaria, cultural y educativa de enorme relevancia. En este sentido, entendemos que es necesario, además de mantenerlos y potenciarlos, que sean reconocidos por las instituciones públicas como programas universitarios equiparables a los programas de las titulaciones oficiales.

En resumen, la educación de personas adultas ha experimentado importantes transformaciones en los últimos tiempos. Su marcado carácter compensatorio en la perspectiva de la educación formal se ha visto ampliado desde el último tercio del siglo XX. Sin olvidar esta consideración para aquellos sujetos que no tuvieron oportunidades en las primera etapas de la vida, hoy la educación adultos aparece más escorada hacia tres horizontes interconectados: la dimensión personal (aprender a ser: dimensión cívica), el contexto económico y sociolaboral cuya expresión más dinámica se alcanza en las múltiples tareas de la formación continua y, finalmente, asumiendo un interés particular por el colectivo de las personas mayores. 


\section{Otra mirada: la inclusión de la mujer en el universo educativo}

En este apartado vamos a examinar algunas de las repercusiones que ha tenido en el discurso pedagógico el reconocimiento efectivo de la igualdad de género y la inclusión de las mujeres en el sistema educativo. Para ello, vamos a exponer, por un lado, el tratamiento que ha recibido el género en diferentes modelos educativos y, por otro, algunas de las reflexiones y hallazgos que nos ha permitido esta expansión de la educación.

Hasta hace relativamente poco tiempo, ha predominado la concepción de la mujer como un ser biológica e intelectualmente inferior. Este prejuicio sexista ha supuesto uno de los obstáculos más importantes con los que ha tenido que enfrentarse la mujer para acceder a ámbitos tan importantes como el de la política formal, el mundo laboral y el sistema educativo. Tendremos que esperar a la llegada de la modernidad, en la que se fraguan las ideas igualitaristas y emergen los movimientos feministas, para que aquella concepción sea cuestionada y se inicie la lucha por la igualdad de derechos y de oportunidades entre hombres y mujeres. En este contexto, el acceso a la educación formal, al trabajo remunerado y a la participación política se constituyeron como algunas de las reivindicaciones centrales del feminismo de la igualdad. La igualdad entre hombres y mujeres se alcanzará, para esta expresión del feminismo, a través de un trato igualitario que no haga distinciones por razón de género. Sin embargo, refiriéndonos al ámbito que nos ocupa, el conocimiento profundo de lo que acontece en el aula gracias a un número importante de investigaciones que se han realizado sobre la reproducción del patriarcado y las discriminaciones de género (Acker, 1995; Brullet y Subirats, 1992) nos hace pensar que, si bien la entrada de la mujer a la educación ha supuesto un avance fundamental en el camino hacia la igualdad entre hombres y mujeres, no ha sido capaz de superar algunos vestigios sexistas que todavía arrastra nuestro sistema educativo.

Ciertamente, el acceso a la educación ha supuesto un punto de inflexión en la lucha de la mujer por la liberación y la igualdad. La educación ha sido 
(es) una de las llaves que más puertas ha abierto a las mujeres: el acceso al mercado laboral y, consecuentemente, a la independencia económica, el derecho a la participación política, la libertad de elegir entre diferentes estilos de vida, la posibilidad de concebir la maternidad como una opción, son algunos ejemplos de lo que queremos decir. Sin embargo, todavía hoy la educación tiene mucho que hacer en este terreno. Si hacemos un breve repaso sobre las transformaciones que se han producido en la institución escolar gracias a la presión de las mujeres y de los movimientos educativos progresistas, observaremos qué ha supuesto la inclusión de la mujer como sujeto educativo y el camino que nos queda por recorrer.

La escuela tradicional, a finales del siglo XIX y principios del XX, abrió sus puertas a las mujeres y les permitió formarse; sin embargo, se trataba de una escuela segregadora que reproducía las relaciones de poder y las discriminaciones de género en base a las diferencias biológicas entre hombres y mujeres. Es decir, niños y niñas asistían a la escuela, pero estudiaban y aprendían cosas diferentes. El proceso de socialización selectiva diferenciada formaba a los niños para la dominación y para ocupar los espacios públicos y económicos relevantes, y preparaba a las niñas para desarrollar mejor su función como futuras esposas y madres (Ayuste, 2005) La institución escolar contribuía así a legitimar las relaciones de subordinación y de dependencia de la mujer respecto al hombre y asignaba un valor secundario o marginal a todo aquello que pudiera identificarse en el conocimiento académico como femenino.

La escolarización segregada se prolonga en España hasta la implementación de la Ley General de Educación de 1970, momento en el que, gracias a la presión de los movimientos feministas y de renovación pedagógica(10), se crea la escuela mixta y se unifican currículos y trayectorias educativas. La escuela mixta no hace diferencias entre niños y niñas y, gracias a ello, las mujeres han

(10)Experiencias como la Escuela Nueva (1888-1939) o la coeducación defendida por Ferrer i Guardia (1901-1909) son algunos de los antecedentes más importantes de una educación igual para niños y niñas. 
podido acceder a la educación postobligatoria y progresivamente a puestos de mayor responsabilidad social. No obstante, juntar a niños y niñas en un mismo espacio para que aprendan todos lo mismo no significa acabar con el sexismo escolar. La tendencia homogeneizadora del currículum tiende a neutralizar las diferencias a favor del grupo hegemónico; es decir, a favor de la cultura y los valores masculinos en este caso. Ahora, niños y niñas comparten espacios, conocimientos y actividades, pero éstos tienden a invisibilizar las aportaciones de las mujeres y las discriminaciones sexistas a las que se vienen enfrentando históricamente. Por otra parte, como plantean Subirats y Brullet,

el doble tratamiento de devaluación de las actitudes consideradas femeninas y de menor atención a las niñas como individuos — unido a otras características sexistas de la cultura transmitida, (...) — produce unos efectos específicos sobre las niñas, efectos distintos de los que se observan en otros tipos de discriminación que operan en la escuela. En efecto, si bien la diferencia de origen social y cultural de alumnos y alumnas tiene como consecuencia una diferencia en el rendimiento escolar y en las calificaciones y títulos obtenidos, los rasgos sexistas de la educación no se manifiestan actualmente en diferencias de rendimiento, hecho que contribuye a la invisibilidad de esta forma de discriminación, dado que el éxito de una educación suele medirse por tales rendimientos (Subirats y Brullet, 2002, p. 158).

Con todo, se mantiene una diferencia notable en la generización de determinadas trayectorias académicas y profesiones y en los rendimientos económicos que éstas producen.

Asimismo, la falta de correspondencia entre el fracaso escolar y el sexismo ha hecho que este tipo de discriminación pasara inadvertido respecto a otros en los que sí se constata una relación directa, como es el caso de la extracción socioeconómica. En este sentido, el sexismo que se da en la escuela mixta no hay que buscarlo en el rendimiento académico sino en el proceso de construcción de la personalidad y de la identidad. El currículum oculto tiende a depreciar aquello que tiene que ver con 10 femenino y a adoptar el comportamiento masculino como canon. Esto puede observarse fácilmente, por ejemplo, en el uso del lenguaje por parte del profesorado, en las expectativas diferenciadas en relación al género, en las distintas interacciones cuando tratamos de relacionarnos 
con niños o con niñas, así como en la ausencia de las aportaciones de las mujeres en el currículum formal o en los materiales educativos.

La escuela coeducativa se ha encargado de poner en evidencia justamente estas discriminaciones y ha puesto de manifiesto cómo el proyecto de la escuela mixta que se establece a partir de una educación igual para todas las personas, pero que no contempla las diferencias de género, culturales, lingüísticas, sociales,... perjudica notablemente a los colectivos débilmente representados en la cultura escolar. Por esta razón, trata de problematizar el sexismo escolar y de buscar fórmulas para introducir la experiencia femenina en el currículum y en la organización institucional. De ahí que construir una escuela coeducativa exija, por un lado, instaurar formas de trato igualitario y, por otro, repensar los contenidos educativos y el sistema de valores y actitudes que se transmiten. Coeducar significa, desde esta perspectiva, educar conjuntamente a niños y niñas en la idea de que hay distintas percepciones del mundo, distintas experiencias y aportes hechos por mujeres y hombres que deben conformar el horizonte común de comprensión, y sin los que no se puede conocer el mundo ni la realidad.

La incorporación de la mujer a la educación como sujeto de pleno derecho y en igualdad de condiciones, y el reconocimiento de su singularidad, nos ha permitido conocer más a fondo el funcionamiento de la institución escolar e introducir nuevos debates y reflexiones educativas. Seguidamente vamos a ver qué ha supuesto para la Teoría de la Educación abrirse a nuevos sujetos y discursos pedagógicos.

Ampliar nuestra comprensión sobre el funcionamiento del currículum oculto. El sexismo escolar es un buen ejemplo de la falta de neutralidad de la institución educativa. Los estudios que se han hecho en torno a las desigualdades de género y a la reproducción del patriarcado en el ámbito educativo muestran, en general, el sesgo de la cultura escolar hacia lo masculino y la invisibilización de las aportaciones de las mujeres y de los valores que se han considerado tradicionalmente femeninos. Este conocimiento mayor de los aspectos latentes del currículum nos permite 
afinar más la acción educativa y buscar mecanismos para superar este tipo de discriminaciones que no son evidentes a primera vista. Nos estamos refiriendo a un determinado uso del lenguaje, a algunas expectativas estereotipadas, a la ausencia de la mujer en los programas escolares 0 a un tipo de organización escolar que premia más la competitividad que la colaboración.

La insuficiencia de las políticas de igualdad de oportunidades. Sin lugar a dudas, el acceso de la mujer al sistema educativo ha sido uno de los factores que más ha contribuido a la igualación entre hombres y mujeres. Sin embargo, la igualdad de oportunidades en la entrada no significa que se den siempre las condiciones para que las mujeres superen la situación de discriminación histórica a la que se han visto sometidas. Como hemos apuntado anteriormente, la escuela mixta no ha conseguido acabar con algunas de las discriminaciones de género más habituales, como es el caso de la feminización de determinados estudios y profesiones 0 , a la inversa, la infrarepresentación de la mujer en determinadas áreas de conocimiento técnico. Por no hablar de otros aspectos que tienen más relación con la vida cotidiana, como la doble jornada de la mujer trabajadora, la feminización de la pobreza o la violencia en contra de la mujer. Ciertamente, la superación de todo esto no depende sólo de la escuela, pero, como mínimo, nos obliga a pensar qué papel debe desempeñar la educación y cómo puede contribuir a fomentar otros comportamientos y valores. De ahí que la Teoría de la Educación se vea enfrentada a nuevos desafíos y parcelas de conocimiento.

La discriminación no siempre se refleja en el rendimiento académico. Otra reflexión que nos ha permitido realizar la inclusión de la mujer en el sistema educativo $\mathrm{y}$, con ésta, los estudios que se refieren a las relaciones de género en la educación tiene que ver con las diferentes formas en las que puede expresarse la discriminación. Habitualmente, el fracaso escolar se ha considerado, por parte de algunas perspectivas teóricas (teorías de la reproducción, pedagogía crítica, etc.), como el desenlace de un sistema educativo que reproduce las relaciones de subordinación propias de una sociedad jerarquizada y desigual. De ahí que una de las discriminaciones 
más estudiadas tenga que ver con la estructura en clases sociales y que el sexismo escolar no haya ocupado un lugar tan destacado. En este sentido, hemos podido ampliar nuestra comprensión sobre los diferentes efectos que provocan determinadas discriminaciones, que en el caso del sexismo escolar no se traduce en malos resultados por parte de las chicas sino en un proceso de desvalorización de lo femenino frente a lo masculino.

Nuevos modelos educativos. La permeabilidad del universo educativo a la mujer y, con ella, a las reivindicaciones feministas, ha comportado la aparición de nuevos modelos educativos. La escolarización segregada dio paso a la escuela mixta y ésta última al modelo de escuela coeducativa. En el transcurso de este proceso, la teoría y la práctica educativa se han visto expuestas a nuevos debates y planteamientos pedagógicos respecto a conceptos capitales como el de igualdad y diversidad. La disyuntiva entre la igualdad de géneros, reivindicado por el feminismo de la igualdad, y el énfasis en la diferencia sexual del feminismo de la diferencia ha penetrado en el ámbito escolar invitándonos a repensar el sentido de estos conceptos y la relación entre ellos. La homogeneización a la que ha dado lugar un proceso de igualación social poco sensible a las diferencias está cediendo el paso a un modelo educativo que intenta reconciliar el derecho a la igualdad y el respeto a las diferencias ${ }^{\wedge 11 \wedge}$. De ahí que el debate actual no se circunscriba sólo a la necesidad de asegurar el acceso de la mujer a determinados derechos y a recibir un trato igualitario, sino al reconocimiento de su especificidad y a la necesidad de incorporar lo femenino en todos los ámbitos sociales, en especial en el de la educación. "

(11) ei feminismo de la igualdad considera que la situación de inferioridad a la que se ven sometidas las mujeres sólo puede cambiarse consiguiendo los mismos derechos que los hombres. Y que la consecución de estos derechos permitiría introducir la mirada de las mujeres en el mundo. Por su parte, el feminismo de la diferencia entiende que la lucha por la igualdad acaba con la diferencia existente entre ser hombre y ser mujer, por lo que reivindica que la liberación de la mujer no está en la oposición a un mundo patriarcal sino en la valoración y el reconocimiento de lo que tradicionalmente se ha considerado como propio de las mujeres. 


\section{Las nuevas tecnologías y los nuevos espacios formativos}

No es hasta principios de los años ochenta cuando el discurso pedagógico empieza a ocuparse de la utilización de la tecnología en la educación. Los argumentos que justifican y reivindican el uso de ésta tienen que ver más con cubrir necesidades sociales que con argumentos pedagógicos (Gros, 2000). El uso de la tecnología no es una reivindicación nacida desde el profesorado sino que, como ocurre muchas veces, la escuela se organiza y responde a una necesidad social. Al principio, esta demanda se concretaba en la necesidad de formar usuarios. La institución escolar respondió con la alfabetización informática, es decir, con cursos sobre el uso del ordenador, los programas básicos, los lenguajes de programación, etc. El problema es que esta formación no fue suficiente, ya que la extensión del uso de la tecnología de la información y la comunicación (TIC) ha alterado y modificado las propias formas de aprender y enseñar. En este sentido, la tecnología, además de ser un objeto de estudio en sí mismo, constituye un medio de aprendizaje que modifica espacios, tiempos y formas de comunicación. De las demandas sociales pasamos a las necesidades pedagógicas coherentes para capacitar a los ciudadanos en la sociedad-red (Castells, 1997).

El discurso pedagógico acostumbra a ser muy permeable a los términos y conceptos que se manejan en cada momento social y cultural. La influencia de las TICs en este momento se evidencia de forma importante en el nuevo vocabulario que se está generando (Cristal, 2002). La influencia del inglés en el vocabulario pedagógico es evidente, siendo difícil, en muchas ocasiones, la traducción y la adaptación de los términos. Este es el caso del uso del prefijo e- que se está utilizando en cientos de expresiones. Los ejemplos, desde luego, son muy numerosos; solamente en el ámbito educativo encontramos: e-leaming, e-content, e-training, e-moderating, e-books, e-tutoring, e-assesment, e-teacbing, e-conferences, etc. Es difícil predecir cuántas de estas expresiones se consolidarán como términos estables de la lengua, pero su uso se va haciendo cada vez más cotidiano y se está incorporando al vocabulario pedagógico habitual. 
Además de los prefijos, el problema de las denominaciones se hace evidente al designar el espacio educativo que se asigna bajo el soporte de las TICs. De este modo, hoy hablamos de educación virtual, aprendizaje en linea, aprendizaje en red, aprendizaje semipresencial, aprendizaje abierto, aprendizaje virtual, campus virtuales, etc.

La palabra virtual tiene diferentes connotaciones. Generalmente usamos este término para referirnos a una irrealidad, una realidad que no es tangible. Sin embargo, en el terreno de la enseñanza a través de la red significa lo que no está limitado por unas coordenadas espacio-temporales determinadas. Un entorno virtual de aprendizaje es sinónimo de un lugar no determinado por el espacio material. El software que permite manejar este espacio se encuentra disponible en un servidor (o servidores) al que acceden los usuarios para utilizar la información, comunicarle, realizar tareas, etc. En definitiva, el proceso de enseñanza-aprendizaje se establece en un espacio situado en la red.

El caso más ilustrativo que nos permite reflexionar sobre la evolución del conocimiento pedagógico a partir del uso de la tecnología lo encontramos en la enseñanza a distancia. Por este motivo, tomaremos como eje central los cambios realizados en este ámbito educativo para mostrar las principales modificaciones que afectan al propio conocimiento pedagógico.

Si tomamos en cuenta la evolución de recursos y la modalidad en la historia de la educación a distancia, según Garrison (1989), encontramos cuatro etapas: enseñanza por correspondencia, enseñanza multimedia, enseñanza telemática y, por último, enseñanza colaborativa basada en Internet.

La educación a distancia se originó producto de los grandes cambios económicos y sociales que se fueron dando en la segunda mitad del siglo XIX. La educación y la formación fueron adquiriendo un modelo industrial ampliando la cantidad y tipos de usuarios. La enseñanza por correspondencia fue el primer tipo de educación a distancia, que comenzó a finales del siglo XIX y principios del XX. Los medios disponibles para el aprendizaje eran los materiales impresos y los servicios postales. No había guía de estudio para los alumnos, sino que simplemente eran clases 
tradicionales presenciales reproducidas e impresas. Posteriormente, se fueron introduciendo guías para ayudar al estudiante, actividades complementarias a cada lección, ejercicios de autoevaluación, etc. Durante muchos años, los únicos medios de interacción eran la correspondencia y el teléfono.

La segunda generación de educación a distancia tiene lugar a partir de 1960 a través de la creación de la Open University en Gran Bretaña. Esta universidad fue pionera en la combinación de varios recursos como el teléfono, la televisión y recursos audiovisuales, como diapositivas, casetes, etc.

El desarrollo de la modalidad a distancia está relacionado con la evolución de las TICs sobre todo a partir de los años 80. Esta fase se caracteriza por la inserción de las telecomunicaciones con otros medios educativos y nace la formación a distancia interactiva a partir del desarrollo de materiales multimedia. En una cuarta etapa, a partir de los años 90, surge la denominada enseñanza abierta fundamentada en el uso de las redes de comunicación. Esta modalidad da un cambio importante, ya que la interacción y la comunicación entre el profesor y los estudiantes, así como entre los propios estudiantes, pasa a ser un elemento central durante el proceso de formación.

También es importante destacar que muchos de estos cambios tienen una clara influencia en la enseñanza presencial, ya que las TICs se van incorporando como elemento de apoyo y también de complemento, como es el caso de la denominada enseñanza semipresencial en la que la interacción cara a cara se combina con la virtual.

La evolución apuntada exige la revisión de determinados aspectos del discurso pedagógico que podemos concretar en los siguientes aspectos:

El tiempo de formación está cada vez menos definido. Fuera del ámbito formal, la formación puede darse a cualquier hora y también en cualquier lugar. Los sistemas de acreditación que se van imponiendo en los modelos universitarios también tienden a flexibilizar la formación, abriendo el acceso no sólo a los estudiantes que se inician por primera vez como continuación de los estudios de bachillerato, sino permitiendo un mayor acceso a personas que ya están trabajando. Aunque se mantienen cursos de larga 
duración, son cada vez más frecuentes las demandas de cursos mucho más específicos que ayuden a adquirir un conocimiento muy preciso. La gestión y organización de la información a partir de un proceso acumulativo y lineal tiende a desaparecer, por lo que cada vez se habla más de «objetos de aprendizaje», es decir, unidades de aprendizaje que contienen información sobre un tema y pueden ser reutilizadas con objetivos formativos diversos.

El espacio formativo también posee una mayor flexibilidad. Actualmente no es necesario coincidir en el espacio y en el tiempo para desarrollar un proceso de aprendizaje y, además, la interacción permite el seguimiento continuo del proceso del estudiante. Tal como se muestra en la figura 1, las posibilidades formativas se diversifican enormemente (Duart-Sangrá, 1999, p. 62).

\begin{tabular}{lll}
\hline & Coincidencia en el tiempo & No coincidencia en el tiempo \\
\hline Coincidencia en el espacio & formación presencial & $\begin{array}{l}\text { autoaprendizaje } \\
\text { teleaprendizaje }\end{array}$ \\
No coincidencia en el espacio & $\begin{array}{l}\text { formación en línea: radio, } \\
\text { televisión, videoconferencia }\end{array}$ & $\begin{array}{l}\text { formación no presencial } \\
\text { enseñanza a distancia } \\
\text { entornos virtuales de aprendizaje }\end{array}$ \\
\hline
\end{tabular}

Figura 1. Diversidad formativa.

La modificación y ampliación de las funciones docentes también es un elemento importante. Las TICs no sólo aumentan el acceso a la información. Introducirlas en la docencia supone a la vez un reto para renovar las formas de planificarla y conducirla y también una oportunidad para poner en evidencia aquellos aspectos menos eficaces de la enseñanza tradicional. Se habla incluso de una situación de shock cultural (Squires, 2000) al describir la enorme ampliación de funciones docentes, al menos en el terreno de lo posible, que las TICs demandan. David Squires considera que la presencia se convierte en telepresencia en varios dominios y roles:

- telepresencia pedagógica: aparece como profesor, en roles de instructor, entrenador, mentor, tutor, proveedor de un andamiaje (scaffolder), experto. 
- telepresencia profesional: aparece como miembro de la profesión docente, en roles como colega, miembro de un comité, enseñante y aprendiz, según los casos.

- telepresencia comercial: aparece como un trabajador por cuenta propia que puede ser contratado, en roles como consultor, tutor personal, editor.

- telepresencia organizacional: aparece como administrador, organizando comités docentes, validando la asistencia y las realizaciones de los estudiantes, administrando la inscripción en los cursos ${ }^{(12)}$.

Por último, es importante señalar el incremento de tecnologías con prestaciones pedagógicas muy concretas y específicas: centradas en la interacción, desarrollo de la colaboración, soporte para el conocimiento científico, etc. Éstas merecen una especial atención, ya que cada vez más se desarrollan tecnologías que fundamentan y apoyan el uso de teorías pedagógicas. En este sentido, hemos pasado de las teorías sobre el diseño instructivo a las teorías sobre el diseño de entornos de aprendizaje que explicitan mucho más la conexión entre la tecnología como elemento mediador y el desarrollo del conocimiento pedagógico (Bereiter, 2002).

5. Los retos medioambientales y la educación

5.1. La problemática ambiental: una mirada desde la Teoría de la Educación

Desde que el pensamiento sobre la educación empezó a operar fuera del marco estricto del sentido común, la construcción de conocimiento

(12) Ver, por ejemplo, http://uniwiki.ourproject.org/tiki-index.php, un proyecto de innovación docente en la Facultad de Biología de la Universidad de Barcelona, donde se evidencia la telepresencia pedagógica, profesional y de gestión de los profesores. 
científico sobre el fenómeno educativo se realiza en base a metáforas 0 instrumentos teórico-metodológicos facilitadores de enfoques desde los que abordar los problemas complejos (Gimeno Sacristán, 2001). Pero, para abordar los problemas complejos que caracterizan a la sociedad actual, no son suficientes ni válidos los instrumentos conceptuales de una disciplina en particular. Si bien la evolución del conocimiento científico se ha caracterizado en el pasado por la fragmentación y el establecimiento de límites entre disciplinas, esta circunstancia es actualmente inviable (Morin, 2001).

La construcción de conocimiento pedagógico implica un constante «ajuste» con la realidad; en esa realidad — conceptual y factual —es donde se encuentran los «materiales» para la elaboración de la Teoría de la Educación. Pero esa realidad, además de compleja, está en constante cambio, por lo que la Teoría de la Educación ha de tratar de producir conocimiento científico innovador para afrontar los retos que presentan las sociedades actuales. Uno de esos retos está representado por la gravedad de la problemática de las cuestiones medioambientales, causantes de procesos de desarrollo que están siendo insostenibles; esta problemática comprende complejas dimensiones, en las que están involucradas estrategias de comportamiento humano y de organización social que son difíciles de formular desde una perspectiva unidimensional, requiriendo soluciones que van más allá de la fragmentación científica y exigiendo el concurso de áreas de conocimiento tradicionalmente fragmentadas.

\subsection{De la educación ambiental a la educación para el desarrollo humano sostenible}

La problemática ambiental empezó a ser no sólo una cuestión política y social sino también educativa a finales de los años sesenta; el final de esta década marca el despegue de nuevas concepciones educativas que tratan de conciliar las exigencias entre las personas y el medio ambiente. Inicialmente, 
y debido a los informes de corte catastrofista(13) generadores del estallido de la conciencia ecológica, la consideración pedagógica sobre el medio ambiente era parcial, por cuanto se centraba en los aspectos del medio ambiente natural, pero el desarrollo de la educación ambiental como nuevo ámbito de reflexión y acción educativas ha venido experimentado una notable emergencia de fenómenos nuevos que han configurando grados crecientes de complejidad sobre su objeto de estudio, los cuales han propiciado cambios significativos a) en el propio término disciplinario (de la concepción de educación ambiental a la concepción de educación para el desarrollo sostenible)(14) b) en el cuerpo de conceptos (de la consideración única del aspecto natural del medio ambiente a la inclusión de aspectos socio-económicos y culturales),

c) en la metodología (de la conservacionista a la regeneracionista, de la pasiva a la activa y participativa) y d) incluso en sus objetivos fundamentales (de la protección ambiental al desarrollo de competencias cognitivas, metodológicas, actitudinales y participativas coherentes con los criterios y valores del desarrollo humano social y ambientalmente sostenible).

La sostenibilidad es un concepto que transciende al propio concepto de medio ambiente, ya que incluye no solamente la búsqueda de la calidad ambiental, sino también la equidad y la justicia social. Estas cuestiones aparecen reflejadas como prioridades en la planificación de los programas y actividades a desarrollar para conseguir los objetivos de la Década de

(13)cabe reseñar los Informes del Club de Roma por representar el primer intento riguroso de abordar los problemas de desarrollo desde la perspectiva de los límites del crecimiento y la búsqueda de modelos de bienestar social más racionales (Meadows, Meadows, Randers y Beherens, 1972; Meadows, Meadows y Randers, 1993).

(14) ei cambio terminológico y conceptual ha sido propiciado fundamentalmente por la emergencia y generalizada aceptación, tanto por los sectores económicos conservadores como por los sectores sociales progresistas, del concepto de desarrollo sostenible (Naredo, 1996) que, aunque se menciona inicialmente en la Declaración de Estocolmo sobre el medio humano en 1972 y se pone en evidencia en el Segundo Informe del Club de Roma en 1972, es acuñado y difundido como principio político en el Informe Brundtland en 1987, se consolida como idea/filosofía/estrategia en la Declaración de Río sobre el Medio Ambiente y el Desarrollo en la Cumbre de la Tierra de 1992 y se ratifica en la Cumbre de Johannesburgo en 2002. La necesidad de operativizar el concepto ha originado el término de glocalización de las acciones, cuya puesta en práctica ha sido impulsada desde las Conferencias Pan-europeas sobre ciudades y villas sostenibles (Aarlborg, 1994; Lisboa, 1996; Hannover, 2000) en las cuales la referencia a la educación para la sostenibilidad es una constante (Aznar Minguet, 2002). 
la educación para el desarrollo sostenible (UNESCO, 2005), tales como: reducción de la pobreza, igualdad de sexos, promoción de la salud, protección del medio ambiente, transformación rural, derechos humanos, comprensión cultural y paz, producción y consumo responsables, respeto a la diversidad cultural, acceso igualitario a las TICs. Con esta declaración, las Naciones Unidas ofrecen una gran oportunidad para consolidar los procesos iniciales de «buenas prácticas» en la comunidad educativa internacional, reorientar las funciones de enseñanza e investigación, generar respuestas creativas a los problemas ambientales y educar para la sostenibilidad del desarrollo.

\subsection{La Teoría de la Educación ante el reto de la sostenibilidad}

Ante el reto de la sostenibilidad, la Teoría de la Educación, en cuanto teoría referida a la práctica, «se mueve» en el espacio de actuación de la educación formal, no formal e informal, aplicando distintos tipos de racionalidad: la racionalidad teórica, la racionalidad práctica y la racionalidad ética.

\section{31. La racionalidad teórica}

La racionalidad teórica permite aplicar conocimiento científico para mejorar la práctica educativa. Esta racionalidad se sitúa en el surgimiento de un renovado aparato conceptual de la ciencia que transciende la objetividad fragmentaria de los análisis reduccionistas del enfoque analítico y mecanicista para, desde explicaciones multidimensionales y comprensivas, ofrecer propuestas epistemológicas y metodológicas más acordes con las ciencias humano-sociales y con la necesidad de conexionar interdisciplinariamente los fenómenos naturales, socio-económicos y culturales del medio ambiente y el desarrollo. Desde esta racionalidad, la Teoría de la Educación se centra en a) revisar y ofrecer propuestas teórico-metodológicas para la comprensión de la problemática ambiental, situando en el contexto de la educación los 
diversos enfoques 0 teorías sobre el desarrollo y la sostenibilidad(15) b) revisar y ofrecer propuestas teórico-metodológicas para la comprensión de la interacción entre los seres humanos y el medio ambiente natural y socio-cultural y c) revisar y ofrecer propuestas teórico-metodológicas para comprender la relación entre el pensamiento y la acción en el despliegue de las competencias que un desarrollo humano sostenible requiere.

\subsubsection{La racionalidad práctica}

La racionalidad práctica posibilita la recreación y nueva construcción de conocimiento desde los «materiales de la experiencia» proporcionados por la aplicación del conocimiento científico en los diferentes ámbitos de actuación. La caracterización tecnológica de la Teoría de la Educación implica una forma de reintegrar la teoría y la práctica educativa que requiere el ejercicio de un saber reflexivo para hacer, pero también un hacer reflexivo para saber. Desde esta racionalidad, la Teoría de la Educación se centra en a) reflexionar críticamente sobre los fines y objetivos de una educación para el desarrollo humano sostenible, b) precisar los conceptos que relacionan medio ambiente, educación, ciencia y sostenibilidad, c) analizar y valorar los informes mundiales sobre el desarrollo(16), d) construir y aportar modelos y sistemas de indicadores para evaluar el proceso de una educación para el desarrollo sostenible (EUROSTAT, 1998; López-Giraldo, 2003), e) construir y aportar modelos de acción pedagógica integral en los

(15) es pertinente en este sentido valorar desde la Teoría de la Educación las implicaciones educativas que los enfoques positivistas (Sanpedro, 1982), la teoría del ecodesarrollo (Naredo, 1998), los enfoques sistémicos (Bunge, 1989; Manzini, 1992; Meadows et al., 1993) y la teoría de la complejidad (Morin, 1994; Morin et al., 2002) pueden tener en la necesidad de repensar el desarrollo y en el proceso de acercamiento a los objetivos de la Década de la educación para el desarrollo sostenible.

(16) los informes anuales que publican organismos internacionales, por ejemplo, el PNUD sobre el desarrollo humano, el Banco Mundial sobre el desarrollo mundial, el Worldwatch Institute sobre la situación del mundo, representan importantes documentos para el análisis y la comprensión de la realidad sobre el desarrollo humano, desde la que plantear opciones de respuesta y propuestas sustentables. 
diferentes niveles del sistema educativo(17) y ${ }_{\mathrm{e}}^{\mathrm{n}}$ los ámbitos no formal e informal de la educación y f) construir y aportar modelos de acreditación de calidad ambiental y sostenibilidad para las instituciones educativas(18).

La idea de desarrollo sostenible no puede quedarse en un simple 0 complejo concepto; su operativización requiere acciones tendentes a definir y evaluar sus indicadores, sobre cuya base aplicar planes de acción integrados, que incluyan un gran despliegue de acciones educativas, a todos los niveles del sistema educativo y en todos los ámbitos en los que se desarrolla la acción educativa, para fomentar los valores de la sostenibilidad, la creación y/o modificación de actitudes que los desarrollen y la permanente actualización de comportamientos que los apliquen.

\subsection{La racionalidad ética}

La racionalidad ética permite cambiar nuestras representaciones sobre la realidad desde un sistema ético; la reintegración teoría-práctica educativa no sólo implica saber y hacer, sino que, «en la medida que actuamos guiados por motivos queridos que tienen que ver con sistemas de valores colectivos, también apela a un tipo de información sobre valores, a un tipo de saber de carácter ético, a compromisos que orientan la educación» (Gimeno Sacristán, 1998, p. 56).

La racionalidad ética de la Teoría de la Educación involucra en la propia definición de desarrollo sostenible la concepción moral y la actitud ética desde la que fomentar los valores de la sostenibilidad; la ética de la sostenibilidad es más que una ética ecológica; es también una ética económica, social y

(17) Desde comienzos de este siglo se empiezan a desarrollar propuestas de «Agendas 21 escolares» como modelo de participación y colaboración con las Agendas 21 locales (Fernández Estolaza, 2002; Aznar Minguet, 2003) y se desarrollan iniciativas alternativas a los rejes transversales» más comprensivas, como está siendo el modelo de »ambientalización institucional» 0 »sostenibilización institucional», que afronta la problemática de la sostenibilidad desde la transversal idad no sólo a nivel de currí́culos, sino también a nivel de gestión y a nivel de la vida y relaciones de la comunidad educativa (Capdevila i Peña, 1999; Rabat, y Geli, 2005).

(18)El progresivo desarrollo de Equipamientos de Educación Ambiental (Escuelas de Educación Ambiental, Escuelas de Natura, Aulas de la Mar, Granjas-Escuela, Centros de Interpretación Ambiental...) exige una permanente revisión de sus objetivos, contenidos, métodos y gestión, de acuerdo a los criterios establecidos en las propuestas de acreditación de calidad educativa que se están aplicando en diferentes Comunidades Autónomas. 
política; es una ética abarcadora de los diferentes ámbitos de interacción — social, ecológica, política, económica... — entre los seres humanos, entre estos y la sociedad y sus instituciones, y también de su interacción con el conjunto de sistemas bióticos y abióticos, tanto desde una óptica intrageneracional como desde una óptica inter-generacional. El conjunto de estas interacciones conforma la triple dimensión de la ética para la sostenibilidad: a) la primera viene definida por los valores que definen los derechos individuales que atañen a las relaciones entre los seres humanos; son los derechos de la primera generación, plasmados en la Declaración Francesa de los Derechos del Hombre y del Ciudadano en 1789; b) la segunda viene definida por los valores que definen los derechos sociales que atañen a las relaciones entre los seres humanos y las organizaciones sociales; son los derechos de la segunda generación plasmados en la Declaración Universal de Derechos Humanos de 1948 y c) la tercera dimensión, no contemplada en la ética tradicional, viene definida por los valores que definen los derechos relacionados con el medio ambiente, la paz y el desarrollo de los pueblos (Escámez, 1998, p. 24) y que atañen a las relaciones entre los seres humanos y el resto de los seres vivos, y aun con los objetos inertes; son los derechos de la tercera generación en proceso de constitución y en torno a los cuales se están dando propuestas para contribuir a la realización de una Carta de la Tierra que pueda configurar una Declaración Universal de los Derechos y Deberes Humanos en relación al Medio Ambiente Natural y Socio-cultural.

Pero es una ética en construcción, cuyo proceso de fundamentación está siendo objeto de debate desde la última década. El cambio de óptica que implica las nuevas consideraciones centradas en la sostenibilidad del desarrollo exige una modificación de los modelos axiológicos tradicionales en los que se han basado las relaciones entre el ser humano y el medio, y en los que la repercusión de las acciones humanas sobre el medio no han formado parte del ámbito de significación ética. En este proceso de cambio el centro de reflexión está siendo bi-polar, entre posturas defensoras de planteamientos antropocéntricos y enfoques éticos biocentristas; proceso de 
cambio en el que no es ajena la Teoría de la Educación, desde la que se aportan argumentaciones que se alejan del antropocentrismo tecnocrático de origen «ilustrado» y desde la que se somete a debate, por una parte, los nuevos planteamientos antropocéntricos de tradición kantiana, como la

ética discursiva representada por Habermas (Habermas, 1989) y matizada por Apple (Apple, 1999) y, por otra, los nuevos modelos éticos biocentristas, defendidos por Jonás (Jonás, 1995) y Morin (Morin, 2001)(19) Ambos enfoques exigen reformulaciones desde la Teoría de la Educación sobre las ideas de reciprocidad, intereses, necesidades, obligación moral, responsabilidad (Escámez y Gil, 2001; Riechmann, 2000) y, desde la clarificación de estas ideas en el marco de la racionalidad ética emergente, la cuestión se ha de centrar en la definición de los principios morales que guíen al ser humano hacia un camino ético y socialmente responsable desde el que conseguir un desarrollo humano ambiental y socialmente sostenible.

\section{La cuestión de la corporeidad en la reflexión pedagógica}

Nuestros cuerpos, lugar de experiencia y ventana al mundo y con el mundo, son al tiempo huéspedes silenciosos de los signos de la cultura (Vilanou, 2001), interpretaciones 0 representaciones de argumentos sociales. La corporeidad, no sólo como sistema biofisiológico, sino como lugar de vivencia del sentir, pensar o hacer, es un espacio nunca completamente cerrado. Como espacio al mismo tiempo subjetivo e impersonal, biológico y atravesado de cultura, el cuerpo ha sido interrogado por diferentes disciplinas, adjetivado por diferentes discursos, educado 0 disciplinado en diferentes contextos educativos. Sea en ámbitos formales,

(19) Para una profundización sobre las aportaciones a la racionalidad ética en la teoría y práctica de la educación para el desarrollo sostenible, ver entre otros: Etcheberría, 1994, Moffat, 1996, Ortega, 2001 y Martínez Martín, 2003. 
no formales e informales, la acción educativa contribuye en gran medida a cómo concebimos nuestro cuerpo, lo experimentamos, lo valoramos.

La ruptura entre los sentidos y la realidad constituye una característica esencial de la modernidad (Bretón, 1995), en la que, ciertamente, las posiciones no dualistas no han sido frecuentes. Esto ha tenido consecuencias en la reflexión pedagógica: la corporeidad, en la educación formal sobre todo, se ha tratado como materia inferior, permitiendo el desprecio, la infravaloración, el castigo, el disciplinamiento que el (bio)poder ha ido ejerciendo sobre los cuerpos (Foucault, 1992), reducidos a una concepción inferior, meramente biológica e instrumental.

En un sentido más general, el lenguaje de los cuerpos (y de las cosas), considerados como artefactos, sigue siendo un lenguaje silencioso(20) en la teoría educativa, que apenas ha tratado de las acciones del cuerpo en sí, del cuerpo real vivido y experimentado, sino del cuerpo-cosa identificado socialmente, basado en la apariencia, dislocado y escindido de la experiencia vivida (en otro lugar, pensado), como tampoco ha tratado de las cosas en sí, sino de sus sustitos conceptuales (Trilla, Ayuste, Romañá y Salinas, 2001). Se trata de un cuerpo escondido, oculto tras un disfraz en las escuelas, las fábricas, los gimnasios, las playas (Bárcena, Tizio, Larrosa y Asensio, 2003, p.126).

Decimos a menudo impropiamente que tenemos un cuerpo, como si no fuéramos lo que somos gracias a él. Pero cabe otra lectura y comprensión de la corporeidad. Merleau Ponty (1975) mostró el cuerpo como «un primer yo natural» inseparable de una visión del mundo y al mismo tiempo visión realizada. La corporeidad, desde esta perspectiva fenomenológica, deviene pues nuestra condición de posibilidad para entrar en el mundo. Y el error, producto de la reflexión que realiza el sujeto, consiste en identificarla como objeto. La identidad humana no es separable de la corporeidad. Si decir cuerpo «es decir una relación de experiencia con el mundo» (Bárcena, Tizio, Larrosa espacio y Goffman (1971) en su análisis de las formas de presentación (roles) en la vida cotidiana. 
y Asensio, 2003, p.126), si decir corporeidad es decir vivencia del sentir o del pensar 0 del hacer, como ya apuntó Zubiri (1986), ¿cómo ha considerado la Pedagogía y, en su caso, la Teoría de la Educación, el valor educativo de la experiencia corporal? Concretaremos un breve recorrido por algunas respuestas.

\subsection{El cuidado de la salud y el trabajo sobre el cuerpo en la escuela}

La atención al cuerpo se introdujo en la escuela sobre todo bajo la influencia del modelo médico biológico. El auge del movimiento higienista en la Europa de la segunda mitad del XIX ${ }^{\wedge 21 \Lambda}$ tuvo como consecuencia el desarrollo de la Higiene Escolar, que introdujo la atención al cuerpo de los educandos desde una perspectiva integral de salud ${ }^{\wedge 22 \Lambda}$. Ciertamente, las ideas educativas básicas de los higienistas no eran nuevas. Ya los griegos clásicos poseían conocimientos empíricos de higiene a través del fomento del ejercicio corporal — la paideia griega integraba el desarrollo físico, intelectual y moral, una idea muy apreciada por muchos higienistas posteriores — mientras que los romanos — de quien hemos heredado la expresión mens sana in corpore sano — dieron al ejercicio físico un carácter más bien militar. Durante toda la Edad Media, sin embargo, se pierde esta consideración y no es hasta el Renacimiento, con su clara reacción al espíritu teológico de la Edad Media y el desarrollo humanista, que se recupera el interés pedagógico por la salud corporal. Comenio habla en su Didáctica Magna (1632) de aulas espaciosas, ejercicio corporal, campos de juego y, en general, de la salud de los

(21) El higienismo, que apareció ligado a avances médicos, al incremento demográfico de las ciudades provocado por la industrialización, a la preocupación por las condiciones de salubridad de la clase obrera y, en el caso que nos ocupa, a la extensión de la escolaridad para todos (una idea extendida desde la Revolución Francesa) y la mejora de sus condiciones materiales. A señalar que estos médicos no se preocupaban únicamente de la salud corporal, sino que opinaban y recomendaban sobre asuntos netamente pedagógicos. Estos aspectos los hemos desarrollado más en Romañá, 2004.

(22) Habitualmente, las obras de Higiene Escolar contenían recomendaciones en una doble vía, las referidas a la salud de los escolares y las referidas a la salubridad y diseño adecuado del edificio escolar, centradas sobre todo en el aula. 
educandos; y, durante los siglos XVII y XVIII, reformadores de la educación como Locke y Rousseau —quien decía que la higiene es menos ciencia que

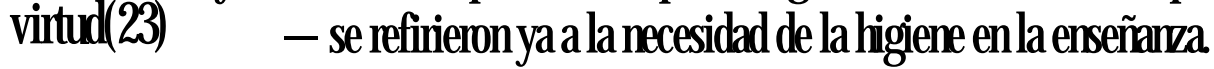

En el siglo XIX, mientras diversos pensadores proponían la modernización de la escuela, las consideraciones higiénicas en los manuales de pedagogía utilizados para la formación de los maestros y maestras seguían siendo escasas, a menudo puramente domésticas(24) y, en general, basadas en apreciaciones de sentido común y a veces erróneas desde un punto de vista científico. Aun así, debemos a un pedagogo, Pedro Alcántara García, el primer Tratado sobre Higiene Escolar en castellano, publicado en 1886, que en su introducción rezaba así:

Considerada la escuela, merced al influjo de dicho sentido, como un lugar de mera instrucción y no como centro de educación — que es lo que debe ser — todo se sacrifica en ella a la enseñanza, por lo que se dejan en punible abandono los intereses del cuerpo, y con ellos otros muy respetables del alma. De aquí la deficiencia y los defectos de que, por lo general, se resiente nuestra educación primaria, y de aquí también la escasa 0 ninguna atención que se ha prestado, y todavía se sigue prestando en muchas partes, a la Higiene Escolar, que ganará terreno en la escuela a medida que lo pierda el intelectualismo, que es su más irreconciliable enemigo.

En suma, la atención a la salud es la primera preocupación educativa positiva en relación al cuerpo, no únicamente referida al bienestar físico, sino también al desarrollo integral del educando en lo intelectual, moral y espiritual.

Paralelamente a la educación higiénica, y estabilizada como disciplina en la escuela, ha discurrido la Educación Física. Habiendo transcurrido por varias formulaciones a lo largo de la historia, durante el siglo XX esta disciplina se ha decantado en tres corrientes educativas sobre el cuerpo (Ros, 2003): la educación físico-deportiva, la educación psicomotriz y la expresión corporal. Aunque a menudo sus cultivadores han entendido la

(23) «La única parte útil de la medicina es la higiene, aunque resulte menos ciencia que virtud» (Rousseau, 1977, p. 46).

(24) «Cuidará el maestro de que se barra diariamente la escuela, abriendo todas las comunicaciones cuando los niños no estén en ella», se decía en el artículo $9^{\circ}$ del Reglamento de las Escuelas Públicas de Instrucción Primaria Elemental, 26 de noviembre de 1838. 
educación física como un factor de educación integral, en la realidad escolar se ha considerado de forma reductiva e incluso marginal, como un tema menor, expresando el modelo axiológico jerarquizador de más larga historia.

\subsection{El discurso axiológico sobre la corporeidad en la Teoría de la Educación}

La corporeidad, aun afectada siempre por las acciones educativas, no se ha constituido como tema central en la teoría educativa(25), $q_{\text {ue }}$ ha tratado el tema preferentemente desde el peso de las ideas, sea considerando el cuerpo como un antivalor, como un valor instrumental al servicio de objetivos espirituales, como una expresión 0 manifestación 0 como una unidad valiosa (Gervilla, 2000). La pregunta, como pregunta «ineludible y previa a la acción educativa» (Gervilla, 2000, p. 106), ha sido «qué cuerpo educar y cómo hacerlo». Y las respuestas, siempre cargadas de valor, han sido buscadas a través un recorrido histórico-filosófico(26).

Al plantear así la indagación, la Teoría de la Educación casi siempre ha acabado subsumiendo la corporeidad en una jerarquía de valores, siguiendo propuestas éticas concretas. Por ejemplo, Gervilla (2000, p. 176), al estudiar el valor del cuerpo en la educación formal,

(25) Con alguna excepción, como García Carrasco y García del Dujo (2001), para los cuales la Teoría de la Educación está escorada hacia una concepción intelectualizada del ser humano. En este sentido, su propuesta es indagar sobre las condiciones previas de posibilidad de la educación, siendo la corporeidad una de ellas. De hecho, ha ocurrido lo mismo con la consideración del entorno físico. Este, profundamente implicado con la corporeidad, salvo en épocas recientes, apenas ha sido considerado relevante en la teoría educativa (Romañá, 1994).

(26) Las respuestas han sido múltiples (Gervilla, 2000): cuerpo cárcel (Platón); cuerpo placer subordinado al alma (epicúreos); cuerpo caído y redimido (Antiguo Testamento); cuerpo templo divino (Pablo de Tarso); cuerpo carne ungida por el Verbo (antioquenos, Tertuliano); cuerpo impedimento del alma (alejandrinos, S. Agustín). En la época moderna, cuerpo cosa que ocupa extensión (res extensa-Descartes); cuerpo y alma manifestaciones de una única sustancia divina (Spinoza); cuerpo signo del alma sensitiva (alma que toma figura-Hegel); cuerpo voluntad objetivada (Schopenhauer); cuerpo afirmación de la vida (Dionisos-Nietzsche); cuerpo unidad significante (existencialismo, fenomenología); cuerpo como rostro ético, epifanía (Lévinas). Y, en la posmodernidad, cuerpo sexduccion, cuerpo narcisista, cuerpo estético, cuerpo indoloro o delpost-deber (todas ellas descritas por Lipovetsky)... 
establece un paralelismo entre la jerarquía axiológica propuesta por M. Scheller(27) y las diferentes valoraciones del cuerpo en la LOGSE:

Terarquía M. Scheler
I0 Valores religiosos $^{0}$ Valores espirituales

$3^{0}$ Valores vitales

40 Valores útiles
Valor del cuerpo

Cuerpo trascendente

Cuerpo estético

Cuerpo ético

Cuerpo social-afectivo

Cuerpo dinámico

Cuerpo instrumental

Cuerpo ecológico

Cuerpo biológico

Este tipo de operaciones supone una sobreconstrucción que, si bien tiene el mérito de señalar los múltiples sentidos de la corporeidad como construcción simbólica, tiene el claro riesgo de, finalmente, ocultar la realidad irreductible de la corporeidad, una realidad no jerarquizada, fluyente y diversa, bajo las diferentes formas e intensidades de condicionamiento en entornos educativos 0 fuera de ellos. En definitiva, la pregunta sobre «qué cuerpo educar» traería entonces un riesgo en su formulación: el monumental olvido de la corporeidad real, que es no sólo una construcción simbólica, sino también, en compleja relación, una experiencia ambiguamente sentida, casi siempre marcada, casi siempre poco consciente(28).

Por lo tanto, es un tema pendiente y previo comenzar por hacer «una historia de la educación como una historia de las operaciones de mareaje,

(27) Scheller, M. (1941). Ética. Revista de Occidente, vol. 1, 151-155. Citado por Gervilla (2000, p. 176).

(28) En Romañá (2003) expongo un ejemplo, referido a las aulas universitarias (segundo y tercer ciclo), de la ignorancia persistente de la corporeidad y el entorno físico en los estudiantes. Esta ignorancia es, en realidad, una forma de inconsciencia, provocada por el planteamiento dualista de nuestra cultura (también la pedagógica). El resultado es que los estudiantes (itambién el profesorado?) no dicen nada de estas cuestiones, no las consideran relevantes en el proceso educativo, ni en la enseñanza-aprendizaje en las aulas. 
configuración y distribución de los cuerpos» y de esta manera dibujar «toda una gramática histórica del cuerpo escolarizado» (Bárcena, Tizio, Larrosa y Asensio, 2003, p. 154), con la inclusión también de todos los fracasos y respuestas divergentes, como signo de la irreductibilidad de la experiencia corporal. Y también es un tema pendiente incorporar a la reflexión pedagógica la cuestión de cómo ve el imaginario colectivo actual la corporeidad, construido desde los mass-media y la publicidad, las producciones cinematográficas y la literatura de ciencia-ficción, las tecnologías médicas o los movimientos sociales como el ecologismo y el feminismo.

Cabe recuperar, finalmente, el legado de advertencias y testimonios de grandes pedagogos. Por ejemplo, Comenio (1632):

Las escuelas enseñan las palabras antes que las cosas, porque entretienen el entendimiento durante algunos años con las artes del lenguaje y después, no sé cuándo, pasan a los estudios reales, las matemáticas, la física, etc., siendo así que las cosas son la sustancia y las palabras el accidente, las cosas el cuerpo, las palabras el vestido, las cosas la médula y las palabras la corteza y la cáscara. Deben presentarse juntamente unas y otras al entendimiento humano; pero, en primer lugar, las cosas, puesto que son el objeto, tanto del entendimiento como de la palabra (1971, pp. 125-126).

También a Rousseau, quien más de un siglo y medio después (1762) nos advertirá del error de saltar de los objetos sensibles a los objetos intelectuales sin pasar por la transformación de nuestras sensaciones en ideas CEmilio, o de la educación, 1977, p. 178). Y a Pestalozzi (1746-1827), desarrollando el método intuitivo que inició Comenio y cincuenta años después al uso del mismo en la Institución Libre de Enseñanza. Y a los humildes Manuales de lecciones de cosas, libros ilustrados que se utilizaron en las escuelas entre 1830 y 1963, para, a través de la observación de las cosas del mundo, evitar el cansancio producido por un exceso de explicación verbal por parte del maestro (Romañá, 2004)(29). y, en el siglo XX, a Dewey (1915), quien señalaba que instruyen el maestro, el libro, las

(29) Mialaret $(1984$, p. 289) reinterpretará la lección de cosas como la observación directa del mundo con todas sus cosas como paso previo a la instrucción científica. 
manos, los ojos, los oídos, todo el cuerpo del aprendiz relacionándose con su entorno. También al movimiento de la Escuela Nueva, dando fundamental importancia al cuerpo del educando en íntimo contacto con la naturaleza.

Hoy, casi siempre al margen del interés teórico-educativo, el cuerpo sigue ejerciendo en otros espacios y tiempos más allá del aula, en donde está tan condicionado y marcado; ejerce en comedores, en patios de recreo, en pasillos, en aseos, en calles, en plazas, en bares, en el corazón de la vida privada... Ejerce, oculto a la mirada teórico-educativa, en actividades escolares como la música, el teatro, las artes plásticas, la literatura. 0, si se quiere, se hace, a veces, Teoría de la Educación desde otras áreas de conocimiento u otras disciplinas, como la educación musical, la educación teatral, la educación plástica, la educación artística, la educación literaria. La corporeidad, mucho más que un hecho biológico, sigue expresándose con otros lenguajes que la Teoría de la Educación habrá de abordar prestándoles mayor atención, observando, mirando humildemente la vida humana y sus expresiones corporales en la escuela y en la calle, en el trabajo y en casa. Expresiones a veces tan cotidianas y simples como un gesto o el uso de un bastón para caminar, a veces tan complejas como el imaginario ficcional que nos rodea, nos constituye y transforma nuestra autocomprensión. 
Acker, S. (1995). Género y educación. Madrid: Narcea.

Alcántara García, P. (1886). Tratado de higiene escolar: guía teórico-práctica. Madrid: Librería de Hernando.

Apple, K.O. (1999). Globalización y la necesidad de una ética universal. Revista Debats, 66.

Ayuste, A. (2005) Intereducación. Teoría de la Educación. Revista Interuniversitária, 17, pp. 49-80.

Aznar Minguet, P. (2002). La escuela y el desarrollo humano sostenible: retos educativos a nivel local. Teoría de la Educación. Revista Interuniversitária, 14, pp. 151-183.

Aznar Minguet, P. (2003). Participación de las agencias educativas en el desarrollo sostenible a nivel local: hacia una Agenda 21 escolar. Revista Española de Pedagogía, 225, pp. 223-242.

Bárcena, F.; Tizio, H.; Larrosa, J. y Asensio, J. M. (2003). El lenguaje del cuerpo. Políticas y poéticas del cuerpo en educación. En Romañá, T. y Martínez, M. (eds.). Otros lenguajes en educación. XXII Seminario Interuniversitário de Teoría de la Educación. Barcelona: ICE de la Universitat de Barcelona, pp. 121-172.

Bereiter, C (2002). Education and mind in Knowledge Age. NJ: Lawrence Erlbaum Associates.

Bokelmann, H. (1981). Pedagogía. En AA.W. Conceptos fundamentales de Pedagogía. Barcelona: Ed. Herder, pp. 594-655.

Bonal, X. (1997). Las actitudes del profesorado ante la coeducación. Propuestas de intervención, Barcelona, Grao.

Bretón, D. (1995). Antropología del cuerpo y modernidad. Buenos Aires: Nueva Visión.

Brundtland, G. H. (1988). Nuestro futuro común. Madrid. Alianza Universidad.

Capdevila i Peña, I. (1999). L'ambientalització de la universitat. liles Balears: D7Edicions.

Castells, M (1997). La era de la información. Madrid: Alianza.

Comenio, J. A. (1971). Didáctica Magna. Madrid: Instituto Editorial Reus, S.A.

Coombs, P. H. (1968). The World Educational Crisis. New York: Oxford University Press, (versión castellana de 1971, La crisis mundial de la Educación. Barcelona: Editorial Península).

Coombs, P. H. (1985). La crisis mundial de la educación. Perspectivas actuales. Madrid: Editorial Santillana.

Coombs, P. H., \& Ahmed, M. (1974). Attacking Rural Poverty: How Non-Formal Education can Help. Baltimore: J. Hopkins University Press, (versión castellana de 1975, La lucha contra la pobreza rural. Aporte de la educación no formal. Madrid: Editorial Tecnos).

Crystal, D. (2002). El lenguaje e Internet. Cambridge: Cambridge University Press.

Delors, J. (Coord.) (1996). La educación encierra un tesoro. Madrid: Ediciones SantillanaUnesco.

Dewey, J. (1918). Las escuelas del mañana. Madrid: Lib. Sucesores de Hernando. 
Duart, J.; Sangra, A (eds.) (1999). Aprenentatge i virtualitat. Barcelona: Edicions UOC.

Escámez, J. (1998) Ética y educación ambiental. En Aznar Minguet, P. (coord.). La educación Ambiental en la sociedad global. Valencia: Ediciones Universitat de Valência.

Escámez, J., \& Gil, R. (2001). La educación en la responsabilidad. Barcelona: Paidós.

EUROSTAT (1998). Indicadores de desarrollo sostenible. Luxemburgo: Oficina de Publicaciones Oficiales de las Comunidades Europeas.

Etcheberría, X. (1994). La ética ante la crisis ecológica. Revista Bakeaz, 5.

Faure, E. (Coord.) (1972). Aprender a ser. Madrid: Alianza Editorial-Unesco.

Fernández Estolaza, A (2002). Educar para la sostenibilidad. Agenda 21 escolar: una guía para la escuela. Gobierno Vasco: CEIDA.

Ferrer, L. (1997). Del paradigma mecanicista de la ciencia al paradigma sistémico. Valencia: Ediciones Universitat de Valencia.

Foucault, M. (1992). Microfisisca del poder. Madrid: Ediciones la Piqueta.

García Carrasco, J. y García del Dujo, A. (2001). Teoría de la educación II. Procesos primarios de formación del pensamiento y la acción. Salamanca: Ediciones Universidad de Salamanca.

Gardner, H. (1991). The unschooled Mind. How Children Think \& Hotv Schools Should Teach. New York: Basic Books.

Garrison, D. R. (1989). Understanding distance education. Londres: Routledge.

Gervilla, E. (2000). Valores del cuerpo educando. Barcelona: Herder.

Gimeno Sacristán, J. (1998). Poderes inestables en educación. Madrid: Morata.

Gimeno Sacristán, J. (2001). Educar y convivir en la cultura global. Madrid: Morata.

Goffman, E. (1971). La presentación de la persona en la vida cotidiana. Buenos Aires: Amorrortu.

Gros, B (2000). El ordenador invisible. Barcelona: Gedisa.

Habermas, J. (1989). Teoría de la acción comunicativa. Complementos y estudios previos. Madrid: Cátedra.

Hall, E. T. (1959). The silent language. New York: Doubleday.

Hall, E. T. (1966). The h id den dimensión. New York: Doubleday.

Jonás, H. (1995). El principio de responsabilidad. Ensayo de una ética para la civilización tecnológica. Barcelona: Herder.

Lopez-Giraldo, J. D. (2003). Jóvenes y sostenibilidad en el siglo XXI. Conjunto de indicadores sobre sostenibilidad. Murcia: Alfa Servicios Ambientales.

Martínez Martin, M. (2003). Una propuesta de aprendizaje ético para la educación ambiental. En Mangas Martín, V. J. (coord.). Educación ambiental y sostenibilidad. Alicante: Ediciones Universidad de Alicante.

Mayan, J. M.; Requejo, A. y Rodríguez, A. (2000). La educación de personas mayores. En IV Congreso Nacional y I Iberoamericano de personas mayores. Sevilla.

Meadows, D. H; Meadows, D. L.; Randers, J. y Behrens, E. (1972). Los límites del crecimiento. Informe del club de Roma. México: F.C.E.

Meadows, D. H; Meadows, D. L. y Randers, J. (1993). Más allá de los límites del crecimiento. Madrid: País-Aguilar. 
Merleau-Ponty, M. (1975). Fenomenología de la percepción. Barcelona: Península.

Montoya, M. (Ed.) (2002). Escuela y educación. Madrid: horas y HORAS.

Morin, E. (2001). Los siete saberes necesarios para la educación del futuro. Barcelona: Paidós.

Morín, E. (2001). La mente bien ordenada. Barcelona: Sex barral

Naredo, J. M. (1996). Sobre el origen, el uso y el contenido del término sostenibilidad. Revista de Documentación Social, 12.

OEI (2004). Educar para el desarrollo sostenible. Década 2005-2014. www.oei.es/decada.

Moffat, I. (1996). Sustainable development principles, análisis and policies. New Cork: Partenón Publishing Group.

Ortega, P., \& Mínguez, R. (2001). Educación moral del ciudadano de boy. Barcelona: Paidós.

PNUD (2004). Informe sobre el desarrollo humano. La libertad cultural en el mundo diverso de boy. http://hdr.undp.org/reports.

Rabat, E., \& Geli, A. Ma ( 2005). Ambientalización curricular de los estudios superiores. Gerona: Ediciones Universidad de Gerona.

Requejo Osorio, A. (1994). (Coord.). Política de Educación de adultos. Santiago de Compostela: Tórculo Ediciones.

Requejo Osorio, A. (2003). Educación permanente y educación de adultos. Barcelona: Ariel.

Riechmann, J. (2000). Un mundo vulnerable. Madrid: Los libros de la Catarata.

Romañá, T. (2003). Cos, entorn, educació: de mem a estança. Revista Catalana de Pedagogía, 2, pp. 213-234.

Romañá, T. (2004). Entorno físico y educación. Reflexiones pedagógicas. Barcelona: P.P.U.

Romañá, T. (2004). Ergonomía en la educación: un suma y sigue. Anuario de Psicología, 35 (4), pp. 475-491.

Ros, C. (2003). Concepción del cuerpo en el área de Educación Física. XXII Seminario Interuniversitario de Teoría de la Educación *Otros Lenguajes en Educación. Sitges: Universitat de Barcelona, http://www.ub.es/div5/site/index.htm Consulta: Junio 2005.

Rousseau, J. J. (1977). Emilio, o de la educación. Madrid: Edaf.

Schön, D. A. (1992). La formación de profesionales reflexivos. Barcelona: Editorial Paidós.

Scribner, S., \& Cole, M. (1973). Cognitive consequences of formal and informal education. Science, 182, 553-559 (trad. Castellana de 1982. Consecuencias cognitivas de la educación formal e informal. Infancia y Aprendizaje, 17, 3-18).

Squires, D (2000). Teacher's new «PETs or the advent of Peripatetic Electronic Teachers. http:// www.connected.org/learn/david.html.

Subirats, M., y Brullet, C. (2002). Rosa y azul: la transmisión de géneros en la escuela mixta. En González, A. y Lomas, C. Mujer y educación (pp. 133-167). Barcelona: Graó.

Toledo, V. M. (2000). Universidad y sociedad sustentable. Una propuesta para el nuevo milenio. Tópicos en educación ambiental, 2 (5), 7-20.

Toulmin, S. (1977). La comprensión bumana. Vol. I. El uso colectivo y la evolución de los conceptos. Madrid: Alianza.

Touriñán, J. (1983). Análisis teórico del carácter formals, no formals e cinformalı de la educación. Papers d'Educació,1, 105-127. 
Trilla, J. (1981). Creatividad, imprevisibilidad y educación informal. En AA.VV, Creatividad y educación (pp. 55-69). Madrid: Servicio de Publicaciones del MEC.

Trilla, J. (1984). La educación no formal. En A. SANVISENS (Comp.), Introducción a la Pedagogía (pp. 337-365). Barcelona: Editorial Barcanova.

Trilla, J. (1985). La educación fuera de la escuela. Barcelona: Planeta (Edición actualizada y ampliada en 1993 y ss., Barcelona, Editorial Ariel)

Trilla, J. (1986). La educación informal. Barcelona: P.P.U.

Trilla, J. (1992). La educación no formal. Definición, conceptos básicos y ámbitos de aplicación. En J. SARRAMONA (Ed.), La educación no formal (pp. 9-50). Barcelona: Ed. Ceac.

Trilla, J.; Ayuste, A.; Romañá, T. y Salinas, H. (2001). Educación y calidad de vida. Las cosas, los otros y uno mismo. En Vázquez Gómez, G. (ed.), Educación y calidad de vida. Madrid: Editorial Complutense, pp. 117-167.

UNESCO (2005). Educación con miras al desarrollo. Decenio de las Naciones Unidas 20052014. Resolución 57/254 de la Asamblea General de Naciones Unidas. http://portal.unesco. org/education/es.

Vilanou, C. (2001). Imatges del cos humà. Apunts. Educació Física i Esport, 63, 94-104.

W. W. I. (2005). La situación del mundo: La seguridad mundial. Madrid: World Watch Institute. Icaria Editorial.

Zubiri, X. (1986). Sobre el hombre. Madrid: Alianza Editorial-Sociedad de Estudios y Publicaciones. 